Revista de Antropología Social

ISSN: 1131-558X

https://dx.doi.org/10.5209/raso.65624

\title{
Conexiones genealógicas: de la gestación a la descendencia
}

María Eugenia Olavarría. 2018. La gestación para otros en México. Parentesco, tecnología y poder. México: Gedisa - UAM.

A diferencia de otras variantes, donde los lazos de sangre no siempre desempeñan el papel que usualmente otorgamos a la descendencia, el parentesco occidental establece un nexo sumamente estrecho entre el parto y la maternidad, de acuerdo con el principio de mater semper certa est, como reza el proverbio latino al asegurar que la maternidad nunca es incierta. A través de las técnicas de reproducción asistida, que desde hace unas décadas han hecho posible la gestación subrogada, los vínculos de la descendencia han dejado, sin embargo, de tener la certidumbre acostumbrada y se presentan hoy en día como el resultado de un proceso social que involucra diversos actores, desde la gestación por sustitución hasta las clínicas de fertilidad. La gestación para otros en México, el último libro de María Eugenia Olavarría es sin duda un escenario donde el poder, el parentesco y la tecnología adquieren el estatuto de actores en un drama social que actualmente afecta a numerosas familias. En manos de una profesional, con la suficiente curiosidad para asomarse por el ojo de la cerradura, la reproducción asistida deja de ser un fenómeno cuantitativamente irrelevante para convertirse en un recurso antropológicamente significativo, cuyas prácticas exceden el universo de la biología y las nuevas técnicas de inseminación artificial. En contra de cualquier expectativa, La gestación para otros en México es un libro en el que los datos biológicos son apenas perceptibles, ya que la información genética parece siempre ubicarse en ese límite que une la naturaleza con la cultura.

Podría reprocharse que este libro seminal, inédito en el horizonte de la antropología mexicana, prolonga la tendencia a convertir la antropología de las sociedades industriales en una especie de ciencia de las anomalías y de las desviaciones, a semejanza de otros estudios contemporáneos que han hecho del grafiti, el metro y las tribus urbanas el campo de sus reflexiones. Sin embargo, el libro de Olavarría aborda un problema marginal para situarlo en el centro de nuestras creencias y nuestras representaciones. La gestación subrogada, en la que una mujer proporciona su vientre para gestar un hijo ajeno, se presenta aquí como un momento etnográfico que interroga de frente nuestras más profundas convicciones acerca de la filiación, la paternidad y el parentesco, columnas vertebrales de una razón genealógica que vincula en nuestras sociedades el origen con la identidad. Gestar seres humanos para otros, ya sea mediante el trasplante embrionario o la inseminación artificial, se vuelve un procedimiento anómalo que altera la estabilidad de nuestras clasificaciones; sin embargo, no es aventurado suponer que esta anomalía deriva de un conjunto de representaciones que son inherentes a la tradición occidental, según la cual el origen define el destino de las identidades futuras. A través de un modelo genealógico, como hace unos años indicaba Tim Ingold (2015), las líneas que conectan antepasados con descendientes se vuelven líneas de transmisión por 
las que transita la información genética, los apelativos familiares y la herencia cultural. De ahí que el término latino para filiación lleve implícita la metáfora de una corriente de sangre y de valores que fluye desde la misma fuente, a la manera de un pasado que se proyecta sin interrupciones hacia el presente, como solemos conceptualizar la historia de nuestras propias sociedades.

La descendencia ha sido, en efecto, el paradigma de la continuidad. La lógica que transforma la descendencia en un conector genealógico ha tenido sin duda repercusiones en nuestra concepción sobre el parentesco, pero también ha sido esencial para forjar la idea de una historia lineal que se presenta a la manera de un linaje con engendramientos sucesivos. De ahí que el libro de Olavarría no sea tan solo un tratado sobre la reproducción asistida, sino un ensayo que versa sobre las representaciones más íntimas en torno a la filiación, la descendencia y la genealogía. Al hacer posible la gestación subrogada, los métodos de reproducción asistida ponen al descubierto la naturaleza ambivalente de la filiación, así como la modernidad ha puesto en evidencia el carácter ambiguo de nuestras alianzas, con vínculos cada vez más diversos que no se limitan al modelo monogámico y heterosexual de las generaciones anteriores. Más que un proceso natural, la descendencia es hoy en día una relación social que involucra los tres símbolos del vínculo materno, representados por el óvulo, el vientre y el reconocimiento legal, sin el cual no existe una filiación socialmente reconocida. Si los primeros son definidos por la genética y la medicina, en calidad de símbolos naturales que tendrían un alcance invariable y universal, el reconocimiento legal constituye en cambio un factor tan variable como las propias sociedades y las culturas, cuyas legislaciones no parecen seguir ningún modelo universal a la hora de regular la descendencia que deriva de la gestación subrogada. Así, solo tres de los 28 países de la Comunidad Europea autorizan expresamente esta práctica, mientras que Francia, Alemania, Italia y España la prohíben. Sobre esta imagen variable se proyectan, según el tipo de alianza e ideología de los protagonistas, "contenidos tradicionales e inéditos del parentesco alrededor de las nociones de matrimonio, de familia, de géneros, masculinidad y feminidad, pero, sobre todo, lo que se entiende por un hijo" (p. 118), como anota la autora, quien además recurre a comparaciones transculturales para mostrarnos que la definición de "hijo" no es un asunto sencillo. Ante el dilema entre la adopción legal y la reproducción asistida a través de donantes externos, ciertos países privilegian la primera opción sobre la segunda, mientras otros consideran que un hijo adoptivo no es realmente tal y tienden a privilegiar las técnicas de reproducción asistida, aun cuando estas involucren la donación de semen o la gestación subrogada.

El libro de Olavarría deja entrever que las técnicas de reproducción asistida originan nuevas categorías y, al crear seres inclasificables, perturban el equilibrio de las taxonomías tradicionales. De hecho, ninguno de los términos puestos en juego parece gozar de un consenso universal que permita establecer legislaciones uniformes. De ahí que los óvulos fertilizados, al igual que los embriones humanos, no sean agentes estáticos frente a la ley ni frente al imaginario de los actores de la reproducción asistida. Aun en los procesos técnicos más recurrentes, como la fertilización in vitro y el congelamiento de embriones, se advierten diferencias culturales que se expresan en el plano jurídico de las naciones industrializadas, donde algunas legislaciones locales prohíben justamente lo que otras autorizan. El hecho de que en ciertos países el estatuto jurídico del embrión se defina a partir de la duodécima semana, mientras otros opten por marcar esa frontera en la vigésimocuarta, es "indicativo de 
la falta de consenso y de unidad sobre la condición humana antes del nacimiento" (p. 221), ya que la frontera que define la humanidad resulta en cada caso una frontera variable. La intención de establecer fronteras relativamente estables en el desarrollo embrionario es, por tanto, el resultado de auténticas "luchas por la clasificación", cuyas oscilaciones no tienen otra finalidad que demostrar el carácter continuo o discontinuo de la evolución prenatal de los seres humanos.

En este paisaje de ontologías múltiples, con nociones distintas sobre la descendencia y la maternidad, México se ha convertido, según la autora, en "las islas Caimán de la reproducción asistida" (p. 58), en virtud de que algunas legislaciones locales terminaron por modificar las leyes vigentes para reconocer las figuras de "madre contratante" y "madre sustituta". Hacia finales de los años noventa, en el Estado de Tabasco, el Código Civil introduce una variante que no solo habría de flexibilizar los términos de la gestación subrogada, sino también promueve una estrecha conexión entre la industria turística y los servicios médicos de reproducción asistida. Actualmente, las clínicas de fertilidad en Villahermosa suelen ubicarse en las instalaciones hoteleras, ofrecen servicios de hospedaje, transporte y traducción, al tiempo que proporcionan recorridos a los sitios más representativos del sureste mexicano. Si bien el término "turismo reproductivo" resulta problemático, en la medida en que estigmatiza una actividad con otros objetivos, deja entrever que la industria de la fertilidad trae aparejada una cadena mundial de trabajo reproductivo, la cual involucra desplazamientos de agencias e individuos, pero también de tejidos y gametos que tienen lugar en la sociedad global, donde los efectos de la circulación atañen por igual a los objetos y las personas.

La autora se pregunta sobre las razones que condujeron a una provincia mexicana, situada en el sureste del país, a convertirse en el paraíso de la reproducción asistida. En efecto, ¿por qué en Tabasco? En su opinión, las razones no solo deben buscarse en los pasillos de la política local y en los vericuetos de las legislaciones estatales, sino en criterios de orden cultural que sitúan a Tabasco como una variante de los sistemas parentales. Influenciada por distintos movimientos migratorios, que han permitido la confluencia de indígenas, afrodescendientes y españoles, la región de Tabasco se distingue por una marcada tendencia hacia las alianzas inestables, de acuerdo "con un modelo de monogamia serial en el que los hijos se habitúan a participar de los sucesivos matrimonios o parejas de sus padres" (p. 71). Más afines a las instituciones afromestizas que a las indígenas, con patrones de residencia matrifocales, los sistemas locales de parentesco contemplan la crianza de hijos ajenos en calidad de "entenados", y en esa medida flexibilizan el esquema monógamo y patriarcal que caracteriza a otras regiones del territorio mexicano. En suma, la flexibilidad del parentesco en Tabasco y su carácter marginal respecto al ethos mesoamericano, conformarían acaso factores de primer orden para explicar la presencia de este enclave en la bioeconomía mundial, donde la posibilidad de recurrir a los servicios de una mujer gestante se desplaza en función de las leyes vigentes, apoyadas en buena medida por el derecho consuetudinario.

El caso tabasqueño, con sus sistemas de parentesco flexible y sus alianzas inestables, representa, sin embargo, la variante local de un principio general, de acuerdo con el cual la descendencia es un problema social y colectivo. Hace unos años, de hecho, Godelier hacía notar que en ninguna parte del mundo son suficientes un hombre y una mujer para gestar un ser humano: “además de Dios y de los ancestros que intervienen de manera regular, en algunas sociedades se recurre a múltiples cogeni- 
tores sin que haya una apropiación colectiva del hijo" (Godelier, 2004: 294). Equivalentes a nuestras técnicas de reproducción asistida, al congelamiento de embriones y a la fertilización in vitro, numerosas sociedades han puesto en marcha mecanismos para solventar los obstáculos de la descendencia, aun cuando ninguno de ellos corresponde a la gestación subrogada, que es sin duda una aportación de la tecnología posmoderna. Sin embargo, como nos recuerda Olavarría, el problema gravitaba ya en las narrativas de la tradición grecolatina y en los mitos de las religiones judeocristianas bajo la figura de la virgen subrogada. La relación entre María y el Espíritu Santo, quien fertiliza el cuerpo de una mujer a través de medios no naturales, tiene en efecto antecedentes en nuestra tradición narrativa: en la mitología griega, Gea entrega el fruto de su embarazo a Atenea, una virgen subrogante que se convierte en madre sin haber tenido relaciones sexuales; en la tradición judía, Sara y Abraham tienen a su hijo a través de la intervención de su sirvienta Ager, "la primera subrogada tradicional sin intervención médica" (p. 299) que da a luz a Ismael, hijo de la pareja fundadora del pueblo de Israel. La mitología occidental anunciaba de esta forma un procedimiento que la tecnología biomédica se ha encargado de actualizar, aun a costa de trastocar las reglas de filiación tradicionales.

Así como Descola $(2002,2012)$ ha abogado recientemente por una antropología de la naturaleza, de la misma forma que Latour (1993) ha propuesto reintegrar la antigua dicotomía entre naturaleza y cultura en el horizonte de nuestra disciplina, el esfuerzo de Olavarría parece consistir en reubicar en un nuevo plano ambos polos de la balanza. ¿Hasta qué punto la reproducción asistida, la fertilización in vitro y la gestación subrogada son métodos naturales o prácticas sociales que derivan de una cultura determinada? El límite que separa la naturaleza de la cultura se vuelve extremadamente difuso cuando los óvulos fertilizados in vitro ingresan en el lenguaje de la filiación, o bien cuando los embriones oscilan entre materiales genéticos y criaturas humanas. El libro de María Eugenia Olavarría parece indicar que nada interroga más esas fronteras que nuestras propias modalidades de reproducción. En su modalidad de reproducción "asistida", la gestación para otros conlleva una relación que es socialmente construida $\mathrm{y}$, en esa medida, niega el carácter natural que las teorías de la descendencia otorgaban a los lazos consanguíneos, basadas en la idea de que no hay nada más natural y objetivo que la transmisión de la sangre. Desde que Schneider (1984) interrogó nuestras nociones sobre el parentesco, sabemos, sin embargo, que la sangre no es tan sólo la sustancia que vincula a padres e hijos, sino un significante que expresa los valores concedidos a la identidad, la descendencia y el origen. El lector se pregunta, por tanto, si las prácticas extremas de la reproducción asistida no terminarán tarde o temprano por minar la vigencia de esos valores tan apreciados por el pensamiento occidental, y si la línea que conecta el origen con la identidad no terminará por desvanecerse en las generaciones futuras. A fin de cuentas, como sugiere esta publicación, comenzamos a vivir en un mundo en el que la gestación ya no es sinónimo de destino, de la misma manera que el origen ya no es la garantía de nuestras propias identidades.

Saúl Millán

Escuela Nacional de Antropología e Historia. México. smillan@prodigy.net.mx 


\section{Bibliografía}

Descola, Philippe (2002). Antropología de la Naturaleza. Lima: Instituto Francés de Estudios Andinos, Lluvia Editores.

- (2012). Más allá de naturaleza y cultura. Buenos Aires: Amorrortu.

Godelier, Maurice (2004). Les métamorphoses de la parenté. París: Fayard.

Ingold, Tim (2015). Lineas: una breve historia. Barcelona: Gedisa.

Latour, Bruno (1993). Nunca hemos sido modernos. Madrid: Debate.

Schneider, David (1984). A Critique of the Study of Kinship. Ann Arbor: University of Michigan Press. 